\title{
The Nutfield Advanced Physics Course
}

\section{P.J. Black, Birmingham J. Ogborn, London}

\section{Background}

The last decade has seen much activity throughout the world devoted to a re-examination of and renewal of the school curriculum, particularly in the sciences and in mathematics. In the United Kingdom, much of this effort has been sponsored by the Nuffield Foundation (which is a body, independent of Government, with funds at its disposal to support ventures that could not readily be financed in other ways). This article reports some of the work on Nuffield Advanced Physics, concerned with physics for students, aged 16-18, in schools.

\section{The Students}

The students for whom the course is intended will normally have taken a public examination in from five to ten subjects at the age of 16 (Ordinary Level General Certificate of Education) and will then specialize in two to four subjects (normally, three) at Advanced Level for two years. Many, but not all, of those taking physics also take mathematics. Common combinations at Advanced Level are mathematics, physics and chemistry, and physics, chemistry and biology. As may be expected, Advanced Level students are a selected section of the total age group, and most of them are continuing at school to the age of 18 in the hope of entering higher education. Decisions regarding entry into higher education usually depend upon the results of this examination.

In physics, roughly half the students go on to some form of higher education involving physics in some way, but less than $10 \%$ will be found studying physics as a principal subject at university. Similar small proportions go on to each of the many subject options open to them at university or college: mathematics, chemistry, biology, medicine, engineering courses of various kinds, and so on.

\section{Schools and Universities}

Besides satisfying those actually involved in its development, the Advanced Level course has to satisfy both those in schools who might teach the course and other courses leading up to it, and those in higher education who teach the students who come from it. In the development of the teachers were involved. During the development period, the course was tried with about 1500 students in about sixty schools. The project continued to expand during the period when materials were prepared for publication, so that by summer 1973 it will have been given to a grand total of some 5000 students. The teachers involved in the trials worked very closely with the Project, providing much feedback information, written and during meetings and visits, which was extremely influential in modifying the early versions of material. University teachers were involved not only as members of a consultative committee, but also in a number of working parties. Universities are willing to accept students from the course, and there is much interest in seeing how well they fare.

\section{Examinations}

Because the two-year Advanced Level course leads to an important public examination, it was essential to ensure that an examination appropriate to the goals of the Nuffield course was available. The examination consists of a variety of types of paper, and includes questions of a kind not usually asked at this level for example, essay questions concerning design problems or philosophical issues which arise out of physics, and short questions testing physical understanding in novel situations, are all used. The course also includes an individual investigation done by the student, the teacher's assessment of it forming part of the examination. The examination is discussed at greater length in the Nuffield Advanced Physics publication, Teachers' handbook, and previous examination papers can be purchased from The Oxford and Cambridge Schools Examination Board, 10 Trumpington Street, Cambridge.

\section{Aims and content of the course}

The aims and content of the course are discussed in the Teachers' handbook, mentioned above, this volume course, both school and university being intended as an introduction to the course as a whole. Space permits here only the briefest summary.

The course is published in the form of 10 units, units 1-8 each having one volume for the teacher and one for the student. In Units 9 and 10, the teachers' and students' books are combined in one volume for each unit. A list of these, and other subsidiary publications, is available from the publisher.

\section{The course as a whole}

Figure 1 gives a summary block diagram of the course. The material is organised into three themes, represented by the three vertical columns in Figure 1: Electricity, fields, action at a distance; The nature of matter and of atoms ; Motion and the analysis of change. Various units touch upon these themes in a variety of ways: some, like Unit 2, Electricity, electrons and energy levels, involve all three, while others, like Unit 4, Waves and Oscillations, keep the student within one mode of thinking for much of the time. It is our view that these three themes represent the principal kinds of thinking in physics, and their presence reflects one of our aims, which is to help the student to understand the structure of the subject.

\section{An endpoint to the course}

In designing the course, we felt it to be important that it should have a structure which would convey a sense of direction and purpose, and that this structure should reflect the powerful interconnectedness of physics. We felt it to be a disadvantage of traditional courses that they tended to be compilations of disconnected topics, without any overall shape. For this reason, the course was, to a considerable extent, designed "backwards" from an endpoint, so that much of the early work in the course finds later applications. The endpoint chosen was a study of the quantum behaviour of light and of electrons leading to simple models of atoms as standing wave systems. The volume, Unit 10 Waves, particles and atoms, containing this material, may prove to be of interest to university teachers, since it offers some novel ideas, particularly a use of graphical and numerical methods for the solution of a one-dimensional Schrodinger equation.

The choice of this topic for the main end-point was not arbitrary. Besides being of the first importance in almost all branches of physical 
Figure 1 Block diagram of the course (omitting individual investigations).

\begin{tabular}{|c|c|c|c|c|}
\hline $\begin{array}{l}\text { Electricity: } \\
\text { fields, action at a distance }\end{array}$ & & $\begin{array}{l}\text { The nature of matter and } \\
\text { of atoms }\end{array}$ & & $\begin{array}{l}\text { Motion and the analysis } \\
\text { of change }\end{array}$ \\
\hline & & $\begin{array}{l}\text { Deformation and fracture of } \\
\text { materials - structure (X-ray } \\
\text { evidence); strength: } \\
\text { composite materials. Unit } 1\end{array}$ & & \\
\hline $\begin{array}{l}\text { Conduction; charge carriers, } \\
\text { current and potential } \\
\text { difference; electrical energy. }\end{array}$ & $\rightarrow$ & \begin{tabular}{l|} 
Electrons; energy levels \\
(electron-atom collision \\
evidence).
\end{tabular} & $\rightarrow$ & $\begin{array}{r}\text { Dynamics: energy changes. } \\
\text { Unit } 2\end{array}$ \\
\hline $\begin{array}{l}\text { Electric charge stored by } \\
\text { capacitors. }\end{array}$ & & $\longrightarrow$ & & $\begin{array}{l}\text { Exponental decay of charge } \\
\text { on a capacitor. }\end{array}$ \\
\hline $\begin{array}{l}\text { Electric field: } \varepsilon_{0} \text {; gravitational } \\
\text { field; } G \text {; inverse-square law; } \\
\text { gravitational potential; } \\
\text { electrical potential. } \quad \text { Unit } 3 \\
\end{array}$ & $\rightarrow$ & $\begin{array}{l}\text { lonic bonding; structure, } \\
\text { forces between and energy } \\
\text { stored by pairs of ions. Unit } 3 \\
\end{array}$ & & \\
\hline & & & & $\begin{array}{l}\text { Waves, superposition; the } \\
\text { electromagnetic spectrum; } \\
\text { mechanical waves; example } \\
\text { of theoretical calculation } \\
\text { of wave velocity. } \\
\text { Oscillations: analysis of } \\
\text { simple harmonic motion; } \\
\text { resonance; standing waves. } \\
\text { Unit } 4\end{array}$ \\
\hline & & $\begin{array}{l}\text { Radioactivity; Rutherford } \\
\text { atom; Periodic Table; } \\
\text { photons, } E=h f . \quad \text { Unit } 5 \\
\end{array}$ & $\rightarrow$ & $\begin{array}{l}\text { Exponential decay, } \\
N / N_{0}=e^{-k t} \\
\text { randomness. }\end{array}$ \\
\hline \multicolumn{5}{|l|}{$\begin{array}{r}\text { Electronics; reactive circuits. } \\
\text { Unit } 6\end{array}$} \\
\hline \multicolumn{5}{|l|}{\begin{tabular}{|l|} 
Magnetic field-electro- \\
magnetic induction; \\
transformers, inductors, \\
motors.
\end{tabular}} \\
\hline \multirow[t]{3}{*}{$\begin{array}{l}\text { Electromagnetic waves } \\
\text { (simple description). } \\
\text { Constancy of } c ; \\
\text { relativity effects. }\end{array}$} & & 4 & & 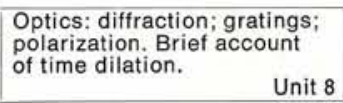 \\
\hline & & & & $\begin{array}{l}\text { One-way and two-way } \\
\text { processes; world fuel } \\
\text { resources; statistical model } \\
\text { of heat flow; absolute } \\
\text { temperature. Unit } 9 \\
\end{array}$ \\
\hline & & $\begin{array}{l}\text { Waves, particles, atoms. } \\
\text { Duality for photons and } \\
\text { electrons. Atoms as standing } \\
\text { wave systems. Uses of wave- } \\
\text { mechanical ideas. Unit } 10\end{array}$ & & \\
\hline
\end{tabular}

science (and we want students to enjoy the feeling that what they are learning has a wide significance), it happens to bring together and use a great number of the fundamental ideas of physics : ideas about particle dynamics, ideas about charges, fields and potentials, ideas about waves and superposition, and ideas about the atomic nature of matter. Given that the students will, many of them, proceed to further education in science or engineering, we felt that the course should aim to help them to understand these fundamental ideas.

\section{Selecting topics}

Our selection of topics is bound to be controversial. Like the architect Mies van der Rohe, we were inclined to think that 'Less means more'; that is to say, that an understanding of a small number of fundamental ideas would be better, for students who will use their knowledge in a wide variety of ways, than a general acquaintance with many topics. This is why Figure 1 does not contain a also place applications near the centre of the stage.

Unit 9 Change and Chance again introduces a new style and some novel ideas. It attempts to develop a statistical understanding of the phenomena associated with the Second Law of Thermodynamics, with the use of a Monte Carlo method applied to the behaviour of an Einstein Model of a solid. This material, and especially the associated computer film, Change and Chance, may also be of interest to University teachers.

\section{Skills and attitudes}

Other aims are reflected in the way topics are learned, rather than in the selection of topics. For example, the skills needed to learn from books will be of the first importance in students' later careers, so several sections of the course are designed with this in mind. In Unit 5, Atomic structure, for instance, students are asked to read selected sections from books, articles or original papers, and to report to one another on what they have found. Similarly, mathematical skills will be needed, so Units 2 and 4 develop ideas about differential equations, using numerical methods of solution where these assist physical insight. Examination questions, and questions in the Students'Books, reflect the need for students to be able to translate information between graphical, numerical, and other forms. The section on ionic crystals, in Unit 3 Field and potential, has a part to play here.

More important than these is the attempt to encourage some independence of thought and action on the part of students. The individual investigations, already mentioned, are important in this respect, but, in addition, a good part of the work of the course, especially experimental work, is individual in nature, with students or small groups of students tackling work on their own and reporting results to the class. The emphasis on reporting itself has a purpose : in our view, understanding physics involves being able to talk sense about physical problems, and talking sense is not an ability which is likely to develop without practice.

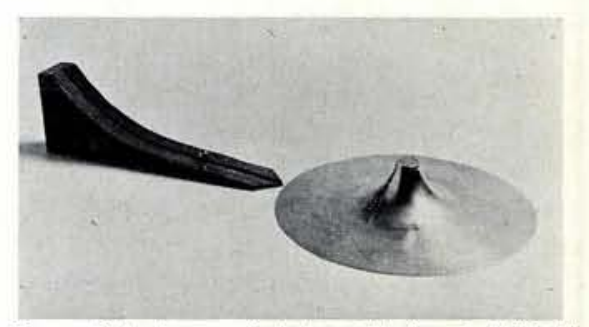

Figure 2 Analogue of alpha scattering in Nuffield Advanced Physics Course 


\section{Conclusion}

The Nuffield Advanced Physics course has been developed over the last four or five years. At the time of writing, the publications are still emerging from the press, and it is too soon to give any account of their reception. So the course is still in its infancy. Those of us who were associated with it, while hoping that the infant is healthy, also hope that it will grow and develop. The last thing we wish to see is adoption of the course in a static and unchanging way, so that the course becomes a new orthodoxy, and a sad case of arrested development. Its future, however, is not now in our hands, but in those of teachers, whose creative efforts are needed to give it life.

\section{Acknowledgments}

Figure 1 is from Nuffield Advanced Physics, Teachers' Handbook, (Penguin Education, 1972)

The publisher is Penguin Education and further information may be obtained from: Penguin Education, Harmondsworth, Middlesex, UK Figure 2 is from photography by M. Plomer.

\section{HORIA HULUBEI}

On 22 November 1972, there ended the meritorious activity, which had gained the recognition of the entire scientific world, of Horia Hulubei, the President of the Romanian National Committee of Physics, scientist of worldwide renown, who died, leaving deep regret not only with those who had the privilege of knowing him but also with the new generation of Romanian physicists.

As words can only dimly evoke a personality so outstanding as that of Horia Hulubei's, we shall confine ourselves to the facts.

Horia Hulubei was born on the 15 November 1897 in lasi where he attended high school and university. In 1926, after taking his degree in physics and chemistry, he left for Paris to obtain his doctorate at the Sorbonne where he joined the group headed by the new Nobel prize winner, Jean Perrin, and where he remained, with brief interruptions, until 1938.

There, in the company of the great names of French physics : Jean Perrin, Marie Curie, Paul Langevin and Aimé Cotton, Hulubei's scientific personality took shape as he established himself as an original researcher. His works, regarded as classical, on Raman effect upon water, the Cauchois-Hulubei spectrometer which exceeded in sensitivity all existing X-ray spectrographic methods and which afforded elaboration of the well-known tables of wavelengths, the recording of the multiple Compton effect as well as the X-lines of the elements 87 and 93, were only a few of his investigations.

$\mathrm{He}$ returned to Romania in 1938. Because of the Second World War which prevented him from continuing his laboratory research, he devoted himself to academic work. He held, at Bucharest University, the Chair of Physical Chemistry subsequently transformed into the Chair of Atomic Physics.

Soon his activity was considerably expanded. As Director of the first Institute for Physics and then of the Institute for Atomic Physics in Bucharest, as well as President of the Committee for Nuclear Energy, he made an invaluable contribution to the development of physics in Romania and to the formation of new generations of physicists. With his unerring competence, hard to overestimate, he co-ordinated the investigations of complex teams of researchers in new fields, such as high energy physics, reactor physics or nuclear reactions, and he militated, without respite, for the stimulation of wide collaboration between physicists to ensure a continuous flow of information and ideas.

$\mathrm{He}$ was elected member of the Academy of the Romanian Socialist

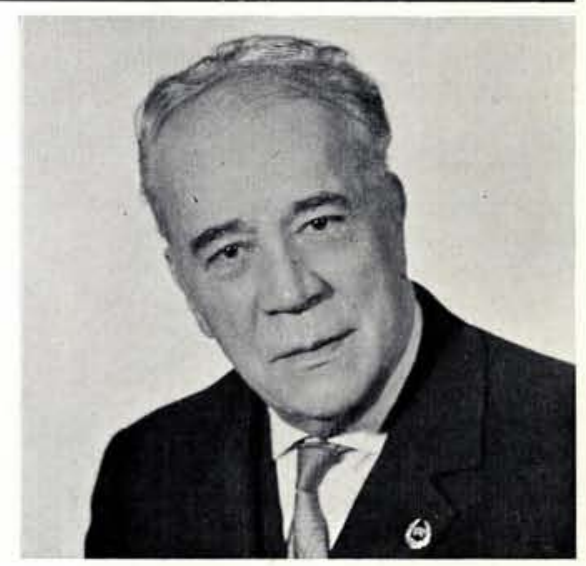

Republic, the French Academy of Sciences, the Academy of Science of Portugal, the Academy of Science of New York, and other scientific societies.

Full of vitality up to the last moments of his life, he took an active part in the World Peace Council, in the Conferences for Nuclear Energy (Geneva), in the scientific councils of the Joint Institute for Nuclear Research in Dubna, as well as in the activity of the International Agency for Atomic Energy, where he played a leading role as Governor, and VicePresident of the Governors' Council.

Paving the way to the development of the most advanced branches of physics, Horia Hulubei appears in perspective as the real founder of modern physics in Romania.

Submitted by the Romanian National Committee of Physics.

\section{Nuclear Physics}

\section{June - 1 July 1972, Aix-en-Provence, France}

The Nuclear Physics Division of EPS held its first large conference from 26 June-1 July in the pleasant surroundings of Aix-en-Provence. The conference was mainly organized by the French Physical Society and was dedicated to the memory of Claude Bloch who died in December 1971 and who had a major influence on post-war French theoretical nuclear physics.

In order that the conference should cover a wide area of nuclear physics while remaining a reasonable size, the programme was centred around three topics, emphasizing different but complementary aspects of the nucleus. The three topics were : I Fission, II Nuclear spectroscopy with heavy ions, III Nuclear physics above $100 \mathrm{MeV}$. There were main invited talks in each of these fields and the conference broke up into parallel sessions for shorter contributed papers in each field. In its format the confer- ence was successful in bringing together what have tended to become somewhat separated areas of the subject.

Fission has in the past been a separate part of nuclear physics. The fission isomers and their explanation in terms of the double hump potential barrier have brought fission back into the main stream of nuclear physics particularly through the predictions of the double hump from the Strutinski synthesis of the microscopic shell model and the macroscopic liquid drop model. Claude Bloch at the time of his death was 